
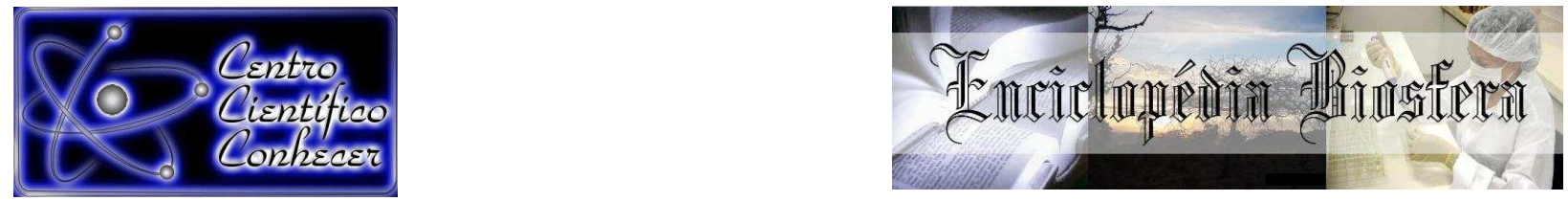

\title{
RIQUEZA FLORÍSTICA DO PARQUE FLAMBOYANT LOURIVAL LOUZA NO MUNICÍPIO DE GOIÂNIA - GO
}

Thaynara da Cunha Ferré1, Rosana Alves Gonçalves², Carlos de Melo e Silva Neto ${ }^{3}$ e Francine Neves Calil ${ }^{4}$

' Engenheira florestal pela Universidade Federal de Goiás (UFG) - Goiânia - Brasil thay.ferre@hotmail.com

2 Ecologa UFG, Mestranda em Agronomia pela UFG, Goiânia, Goiás.

${ }^{3}$ Biólogo UFG, Esp. direito ambiental PUC/GO, Mestre em Biodiversidade Vegetal

UFG e doutorando em Agronomia pela UFG, Goiânia, Goiás.

${ }^{4}$ Engenheira Florestal Universidade Federal de Santa Maria (UFSM), Mestre em Engenharia Florestal pela UFSM e doutorado em Engenharia Florestal pela UFSM, Professora da UFG, Goiânia, Goiás.

Recebido em: 08/09/2015 - Aprovado em: 14/11/2015 - Publicado em: 01/12/2015 DOI: http://dx.doi.org/10.18677/Enciclopedia_Biosfera_2015_223

\section{RESUMO}

bioma Cerrado apresenta uma alta taxa de endemismo que somada a rica diversidade o torna um hotspot. A proteção das áreas utilizando as unidades de conservação, sendo considerado uma das mais eficientes maneiras de se manter a diversidade biológica, e uma das formas de se fazer isso dentro da cidade são os parques urbanos. O conceito de integrar meio urbano e meio ambiente, considerado importante sob inúmeros pontos de vista como econômico, social, político e biológico. Assim o objetivo deste trabalho foi realizar um levantamento florístico, avaliando as espécies arbóreas do Parque Municipal Flamboyant Lourival Louza localizado na cidade de Goiânia, estado de Goiás. O presente trabalho foi realizado entre os meses de abril e Julho do ano de 2014, com o levantamento floristico realizado a uma distância de cinco metros à esquerda e cinco metros à direita da pista de caminhada principal. Na avaliação contabilizou-se 492 indivíduos divididos em 92 e 29 famílias como Arecacea, Fabaceae, Bignoniacea entre outras. Encontrou-se plantas de interesse florestal, paisagístico, e agronômico. As espécies mais frequentes foram: Syagrus oleracea (Mart.) Becc.; Platymiscium floribundum Vogel; Jacaranda cuspidifolia Mart.; Bauhinia brevipis Vog. e Hibiscus rosascinensis L. A riqueza floristica do Parque Flamboyant torna-o relevante para a conservação e manutenção do bioma Cerrado.

PALAVRAS-CHAVE: Árvores, Cerrado, Parque urbano.

\section{FLORISTIC RICHNESS OF FLAMBOYANT LOURIVAL LOUZA PARK IN THE GOIÂNIA CITY-GO}

\begin{abstract}
The Cerrado presents a high rate of endemism which added the rich diversity makes it a hotspot. The protection of areas using the protected area and is one of the most effective ways to maintain biological diversity, and one way of doing this within the ENCICLOPÉDIA BIOSFERA, Centro Científico Conhecer - Goiânia, v.11 n.22; p.2531


city are the urban parks. That behind the concept of integrating urban and environment, considered important from many points of view as economic, social, political and biological. The following research was accomplished at the Flamboyant Lourval Louza Municipal Park located in the city of Goiania, State of Goias, between April and July of 2014. With the objective to accomplish a floristic survey, assessing the species planted in the park a distance of five meters to the left and five meters to the right of the main hiking trail. In this study was counted 492 beings within 92 species and also 29 tree's families such as Arecacea, Fabaceae, Bignoniacea. Moreover, plants with scenic interest, forest interest and agronomic interest, were found. The most frequent species were:Syagrus oleracea (Mart.) Becc.; Platymiscium floribundum Vogel; Jacaranda cuspidifolia Mart.; Bauhinia brevipis Vog. e Hibiscus rosascinensis $\mathrm{L}$. Because of floristic richness of the Flamboyant Park, it is relevant for the conservation and maintenance of the floristic richness of the Cerrado

KEYWORDS: tree, Cerrado, urban park.

\section{INTRODUÇÃO}

No bioma Cerrado existe uma alternância de espécie, o que segundo KLINK \& MACHADO (2005), somado a diversidade de habitats, contribui para uma taxa de endemismo de $44 \%$ da flora. Esta alta taxa de endemismo somada a rica diversidade faz com que o bioma entre para a lista dos hotspots mundiais sendo o bioma que possui a menor porcentagem de áreas sob proteção integral (MITTERMEIER et al., 2005). Dentre as estratégias de conservação do bioma, e consequentemente, da flora, a proteção das áreas utilizando as unidades de conservação é necessária, sendo considerada uma das mais eficientes maneiras de se manter a diversidade biológica (RAMBALDI \& OLIVEIRA, 2003; CARDOSO et al., 2015).

A criação de parques dentro da cidade vem sendo uma estratégia de preservação de remanescentes de florestas dentro do meio urbano, de forma a garantir a biodiversidade (GRANDOLFO et al., 2013). Além de serem usados como alternativa de lazer, pois as árvores e as áreas verdes urbanas contribuem fortemente para a qualidade de vida nas cidades, e também valorizam o ambiente e a estética, além de promoverem um excelente meio para as atividades da comunidade, criando importantes espaços, oportunidades de recreação e educação (MATSUMOTO et al., 2012; REZENDE et al., 2012).

Com cerca de 950.000 árvores inclusas em 328 diferentes espécies arbóreas, com um índice de 0,79 árvore por habitante e como resultado totalizando um Índice de Áreas Verdes - IAV de 94,0 m² de áreas verdes por habitante, Goiânia destaca-se como a cidade mais arborizada do Brasil, segundo informações do Plano Diretor de Arborização de Goiânia (AMMA, 2008). LOBODA \& ANGELIS (2005), afirmam que as áreas verdes são o ícone na defesa do meio ambiente. Logo, por mais que seja considerada uma cidade verde, ainda assim há uma necessidade de integrar a área urbana e meio ambiente, e segundo FERREIRA (2005), uma forma de realizar essa integração é com a utilização de parques urbanos.

De acordo com a Agência Municipal do Meio Ambiente (AMMA, 2012), Goiânia possuía 30 parques urbanos, distribuídos por diversas regiões do município, Sendo o parque Flamboyant um dos principais, por ser reconhecido como cartão postal da cidade, o Parque Flamboyant Lourival Louza. Segundo PRADO (2012), este parque pode ser considerado um espaço de preservação ambiental, um lugar 
de convívio, de sociabilidade, ou sob inúmeros pontos de vista pode ser um espaço econômico, social, político e biológico.

O Parque Flamboyant, como é mais conhecido, constitui um elemento expressivo no conjunto urbano da Cidade de Goiânia e na formação da paisagem conciliando urbanização com conservação de fragmentos do Cerrado na forma de parques urbanos (OLIVEIRA, 2011; CARDOSO et al., 2015). Assim torna-se relevante o estudo das arbóreas para conhecer a riqueza de espécies que pretendese conservar no parque. Tendo em vista o exposto acima, o objetivo deste trabalho foi a realização de um levantamento florístico da vegetação na área urbana do Parque Flamboyant Lourival Louza, Goiânia, Goiás para a identificação e conhecimento da riqueza de espécies da flora arbórea.

\section{MATERIAL E MÉTODOS}

O estudo foi realizado no Parque Municipal Flamboyant Lourival Louza localizado entre as ruas $15,12,46,55,56$ e a Avenida $H$ no bairro Jardim Goiás, Região Sudeste da cidade de Goiânia, estado de Goiás. Ocupa uma área de $125.572,71 \mathrm{~m}^{2}$ e $1937,53 \mathrm{~m}$ de perímetro (PRADO, 2012)( Figura 1). Os dados foram coletados no período entre abril e julho do ano de 2014, em diversos períodos do dia.

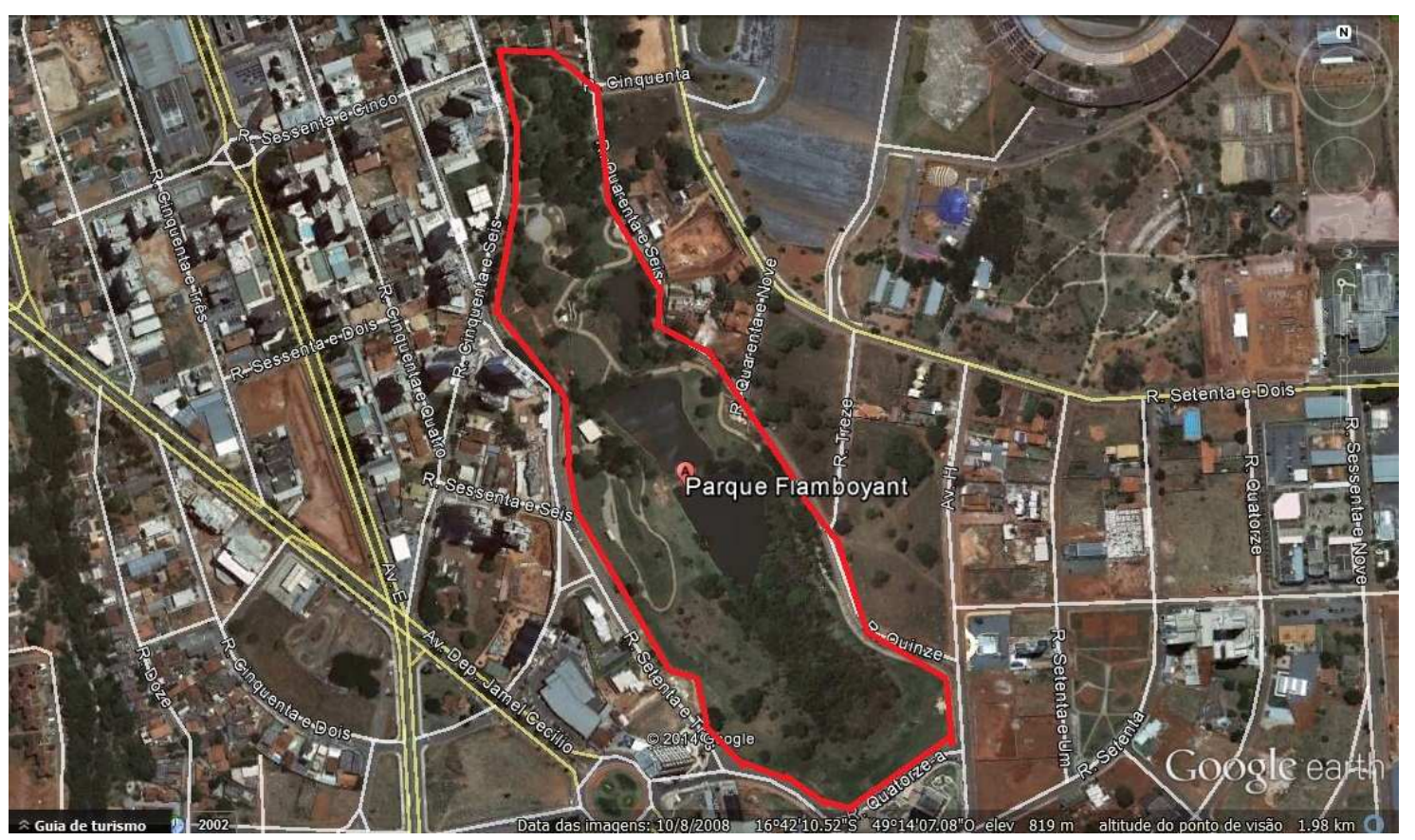

FIGURA 1. Imagem de satélite do Parque Flamboyant Lourival Louza, Goiânia, Goiás. Fonte: Google Earth, 2008.

A metodologia utilizada para o levantamento florístico foi o caminhamento, adaptada de FILGUEIRAS et al. (1994). Dentre as arbóreas do parque, foram avaliadas as espécies plantadas a uma distância de cinco metros à esquerda e cinco metros à direita da pista de caminhada principal.

As espécies foram registradas com câmera fotográfica, tiveram material botânico (vegetativo, e reprodutivo quando encontrado) coletado com auxilio de tesoura de poda e as coordenadas geográficas marcadas com GPS. O material ENCICLOPÉDIA BIOSFERA, Centro Científico Conhecer - Goiânia, v.11 n.22; p.2533 2015 
botânico foi identificado com auxílio de chaves de identificação botânica (BARROSO et al. 1991) e também comparado com material botânico do Herbário da Universidade Federal de Goiás.

Para avaliação descritiva das espécies, foi realizada abundância absoluta e frequência relativa para o conjunto das espécies. Para destacar as principais famílias botânicas foi realizado gráfico de barra de acordo com o número de espécies por família botânica (Metodologia adaptada de SILVA-NETO et al., 2014).

\section{RESULTADOS E DISCUSSÕES}

Próximo a pista de caminhada, foram contabilizadas 492 plantas, 92 espécies divididas em 29 famílias. Dentro desse número foram encontradas 12 plantas mortas, confome mostra a tabela 1. Fabaceae foi a família com mais espécies representantes, contendo 28 espécies, seguida de Rubiacea com nove, Anacardiaceae com sete, Bignoniaceae com seis, Myrtaceae com cinco, e Malvaceae e Meliaceae ambas com quatro espécies (Figura 02). As famílias botânicas encontradas na área são frequentes dentre as famílias botânicas em floresta estacional do Cerrado (PEREIRA et al., 2011). Na tabela 1 estão apresentadas todas as espécies de plantas encontradas no parque.

Dentre as espécies mais frequentes no parque estão: Syagrus oleracea (Mart.) Becc. (gueroba), uma planta ornamental tendo bom potencial para uso no paisagismo, com fácil cultivo por não ser exigente no fator fertilidade (SANTELLI, 2005); o Plastyniscium floribium Vogel, (jacarandá e jacarandá do litoral) é uma planta perenifólia, considerada uma planta ornamental, principalmente no período de floração, podendo ser utilizada no paisagismo e usada em reflorestamentos mistos destinados à recomposição de áreas degradadas de preservação permanente (LORENZI, 2008); o Jacaranda cuspidifolia Mart. (caroba, jacarandá ou carobeira) é extremamente ornamental, principalmente no período de floração, é muito usada na arborização e ornamentação de ruas principalmente pela beleza das flores (LORENZI, 2008); a Bauhinia brevipes Vog. é um arbusto escandente tem altura de $3,0 \mathrm{~m}$, sendo um arbusto do cerrado, uma espécie decídua, as flores e frutos desta, aparecem de junho-agosto, depois da frutificação, perdem todas as folhas no período entre maio-agosto (CORNELISSEN \& FERNANDES, 2001; SILVEIRA et. al., 2006); o Hibiscus rosa-sinensis L. é uma planta ornamental,originária da Ásia tropical e do Havaí, utilizada para a urbanização e paisagismo, alcançando até cinco metros de altura (SILVA \& FIGUEIREDO, 2010). A espécie possui floração do tipo contínua, podendo apresentar floração tanto no período seco quanto no período chuvoso (NEWSTROM et al., 1994; LORENZI \& MOREIRA, 1995; LUND et al., 2006).

TABELA 1. Espécies botânicas encontradas próximas a pista de caminhada principal do parque Flamboyant Louzada Louza, Goiânia, Go (AA Abundância absoluta; FR - Frequência relativa).

\begin{tabular}{cccc}
\hline Nome científico & Família & AA & FR \\
\hline Syagrus oleracea (Mart.) Becc. & Arecaceae & 99 & 0,201 \\
Platymiscium floribundum Vogel & Fabaceae & 29 & 0,058 \\
Jacaranda cuspidifolia Mart. & Bignoniaceae & 26 & 0,052 \\
Bauhinia brevipis Vog. & Fabaceae & 19 & 0,038
\end{tabular}


Hibiscus rosascinensis $\mathrm{L}$.

Piptadenia gonoacantha (Martius) Macbride

Licania tomentosa Benth. Morta

Swietenia macrophylla King Handroanthus pentaphylla (L.) Mattos

Swartzia cf. oblata Cowan

Tabebuia roseo-alba (Ridl.) Sand.

Anadenanthera macrocarpa (Benth.) Brenan

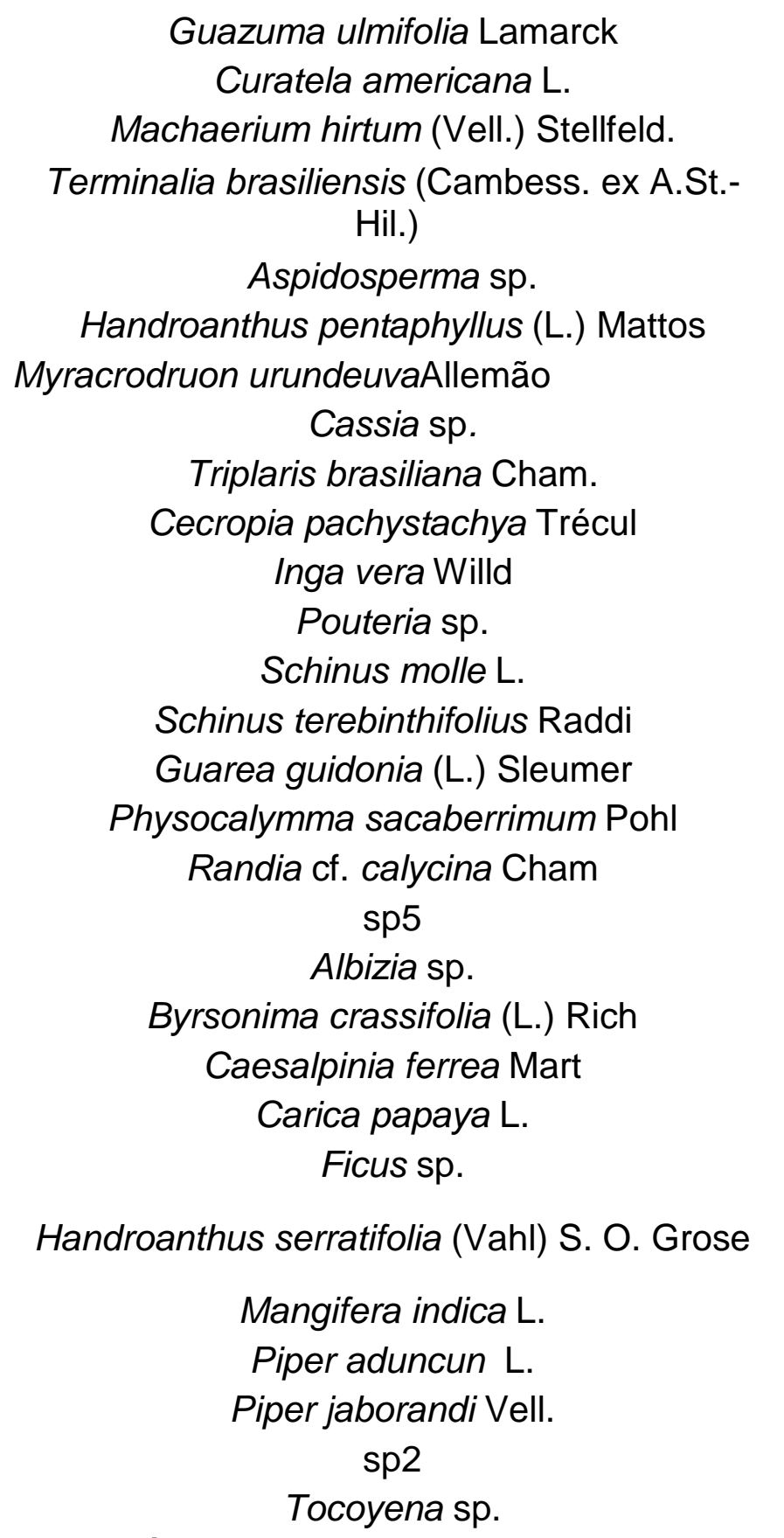

$\begin{array}{crc}\text { Malvaceae } & 19 & 0,038 \\ \text { Fabaceae } & 15 & 0,030 \\ \text { Chrysobalanaceae } & 13 & 0,026 \\ & 12 & 0,024 \\ \text { Meliaceae } & 12 & 0,024 \\ \text { Bignoniaceae } & 10 & 0,020 \\ \text { Fabaceae } & 10 & 0,020 \\ \text { Bignoniaceae } & 10 & 0,020 \\ \text { Fabaceae } & 9 & 0,018 \\ \text { Malvaceae } & 9 & 0,018 \\ \text { Dilleniaceae } & 8 & 0,016 \\ \text { Fabaceae } & 8 & 0,016 \\ \text { Combretaceae } & 8 & 0,016 \\ \text { Apocynaceae } & 7 & 0,014 \\ \text { Bignoniaceae } & 7 & 0,014 \\ \text { Anacardiaceae } & 7 & 0,014 \\ \text { Fabaceae } & 6 & 0,012 \\ \text { Polygonaceae } & 6 & 0,012 \\ \text { Cecropiaceae } & 5 & 0,010 \\ \text { Fabaceae } & 5 & 0,010 \\ \text { Sapotaceae } & 5 & 0,010 \\ \text { Anacardiaceae } & 5 & 0,010 \\ \text { Anacardiaceae } & 5 & 0,010 \\ \text { Meliaceae } & 4 & 0,008 \\ \text { Lithraceae } & 4 & 0,008 \\ \text { Rubiaceae } & 4 & 0,008 \\ \text { Arecaceae } & 4 & 0,008 \\ \text { Fabaceae } & 3 & 0,006 \\ \text { Malpighiaceae } & 3 & 0,006 \\ \text { Fabaceae } & 3 & 0,006 \\ \text { Caricaraceae } & 3 & 0,006 \\ \text { Moraceae } & 3 & 0,006 \\ \text { Bignoniaceae } & 3 & 0,006 \\ \text { Anacardiaceae } & 3 & 0,006 \\ \text { Piperaceae } & 3 & 0,006 \\ \text { Piperaceae } & 3 & 0,006 \\ \text { Rubiaceae } & 3 & 0,006 \\ \text { Rubiaceae } & 3 & 0,006 \\ \text { Goiânia, v.11 n.22; p.2535 } & 2015 \\ & & \end{array}$


Hymenaea courbaril L.

Albizia sp.

Anacardium occidentale L.

Anadenanthera falcata (Benth.) Speg

Attalea sp.

Cariniana estrellensis (Raddi) Kuntze

Cedrela fissilis Vell.

Clitoria fairchildiana R. A. Howard

Copaifera langsdorffii Desf.

Dalbergia cf. nigra (Vell.) Allemão ex Benth.

Delonix regia (Bojer exHook.) Raf.

Inga cylindrica (Vell.) Mart.

Psidium guajava Linn.

sp1

Spathodea campanulata P. Beauv.

Thuja orientalis L.

Tibouchina sp.

Vernonia condensata Baker

Lophantera lactescens Ducke.

Andira sp.

Apeiba tibourbou

Aspidosperma sp2

Azadirachta indica A. Juss.

Bougainvillea spectabilis Willd.

Bowdichia virgilioides Kunth

Calliandra sp.

Cestrum nocturnum L.

Clusia sp.

Coffea arabica L.

Cupressus sp.

Enterolobium contortisiliquum (Vell.) Morong

Erythrina mulungu Mart. ex. Benth

Eugenia cf. uniflora L.

Eugenia sp.

Eugenia sp.2

Heliconia sp.

Inga laurina (Sw.) Willd.

Machaerium sp.

Matayba sp.

Muntingia calabura L. $\begin{array}{lll}\text { Fabaceae } & 2 & 0,004\end{array}$

$\begin{array}{lll}\text { Fabaceae } \quad 2 & 0,004\end{array}$

$\begin{array}{lll}\text { Anacardiaceae } \quad 2 & 0,004\end{array}$

$\begin{array}{lll}\text { Fabaceae } \quad 2 & 0,004\end{array}$

Araliaceae 20,004

$\begin{array}{lll}\text { Meliaceae } & 2 & 0,004\end{array}$

Meliaceae 20,004

$\begin{array}{lll}\text { Fabaceae } & 2 & 0,004\end{array}$

$\begin{array}{lll}\text { Fabaceae } & 2 & 0,004\end{array}$

$\begin{array}{lll}\text { Fabaceae } & 2 & 0,004\end{array}$

$\begin{array}{lll}\text { Fabaceae } & 2 & 0,004\end{array}$

$\begin{array}{lll}\text { Fabaceae } & 2 & 0,004\end{array}$

$\begin{array}{lll}\text { Myrtaceae } 2 & 0,004\end{array}$

$\begin{array}{lll}\text { Rubiaceae } 2 & 2,004\end{array}$

$\begin{array}{lll}\text { Bignoniaceae } 2 & 0,004\end{array}$

$\begin{array}{lll}\text { Cupressaceae } & 2 & 0,004\end{array}$

$\begin{array}{lll}\text { Melastomataceae } \quad 2 & 0,004\end{array}$

$\begin{array}{lll}\text { Asteraceae } 2 & 0,004\end{array}$

Malpighiaceae $\quad 1 \quad 0,002$

$\begin{array}{lll}\text { Fabaceae } \quad 1 & 0,002\end{array}$

$\begin{array}{lll}\text { Malvaceae } & 1 & 0,002\end{array}$

Apocynaceae $1 \quad 0,002$

$\begin{array}{lll}\text { Meliaceae } \quad 1 & 0,002\end{array}$

Nyctaginaceae $1 \quad 0,002$

$\begin{array}{lll}\text { Fabaceae } & 1 & 0,002\end{array}$

Fabaceae $\quad 1 \quad 0,002$

Rubiaceae $\quad 1 \quad 0,002$

Clusiaceae $\quad 1 \quad 0,002$

Rubiaceae 10,002

$\begin{array}{lll}\text { Cupressaceae } \quad 1 & 0,002\end{array}$

$\begin{array}{lll}\text { Fabaceae } & 1 & 0,002\end{array}$

$\begin{array}{lll}\text { Fabaceae } & 1 & 0,002\end{array}$

$\begin{array}{lll}\text { Myrtaceae } & 1 & 0,002\end{array}$

$\begin{array}{lll}\text { Myrtaceae } \quad 1 \quad 0,002 & \end{array}$

$\begin{array}{lll}\text { Myrtaceae } \quad 1 & 0,002\end{array}$

Heliconiaceae $1 \quad 0,002$

Fabaceae $\quad 1 \quad 0,002$

Fabaceae $\quad 1 \quad 0,002$

Sapindaceae $\quad 1 \quad 0,002$

Muntingiaceae $\quad 1 \quad 0,002$ 
Não identificada

Pachira aquatica Aubl

Peltophorum dubium (Spreng.) Taub.

Platyplodium elegans Vog.

Psidium sp.

Schizolobium parahyba (Huber ex Ducke)

Barneby

sp3

$\mathrm{sp} 4$

sp6

Spondias purpurea L.

Tapirira guianensis Aubl

\begin{tabular}{ccc} 
& 1 & 0,002 \\
Malvaceae & 1 & 0,002 \\
Fabaceae & 1 & 0,002 \\
Fabaceae & 1 & 0,002 \\
Myrtaceae & 1 & 0,002 \\
Fabaceae & 1 & 0,002 \\
Rubiaceae & 1 & 0,002 \\
Rubiaceae & 1 & 0,002 \\
Rubiaceae & 1 & 0,002 \\
Anacardiaceae & 1 & 0,002 \\
Anacardiaceae & 1 & 0,002 \\
& 492 & 1,000 \\
\hline
\end{tabular}

Como nota-se, as cinco espécies que são mais frequentes no limite avaliado tem uso paisagístico, sendo adequadas para um parque urbano. Uma das espécies que são frequentes e é um exemplo de planta que não deve ser recomendada para paisagismos, é a Swartzia oblata Cowan mais conhecida como bainha de galinha, pois possui um fruto grande, que ao cair pode provocar acidentes. Outras espécies que foram observadas, são as de interesse agronômico, em especial pode ser citada a Mangifera indica ou mangueira, uma frutífera dicotiledônea, originária da Ásia (SILVA, 2006). Segundo FONSECA (2002), tem se destacado por ser uma das frutíferas mais exportadas no mundo, sendo o Brasil um dos principais produtores. As outras espécies que aparecem e são deste tipo de interesse são Anacardium occidentallis (caju), Carica papaya (mamão), Coffea arabica (café) e Psidium guajava (goiaba).

Com somente três indíviduos em todo o parque, o Delonix regia (Bojer ex Hook.) Raf. (Flamboyant), espécie que o nomeia, aparece duas vezes próximo a pista de caminhada principal. Esta árvore pertencente à família Fabaceae, é adequada para ser usada em paisagismo e arborização de parques e jardins, por ser extremamente florífero e ornamental (LORENZI et al., 2003; BRUN \& MUNIZ, 2006). 


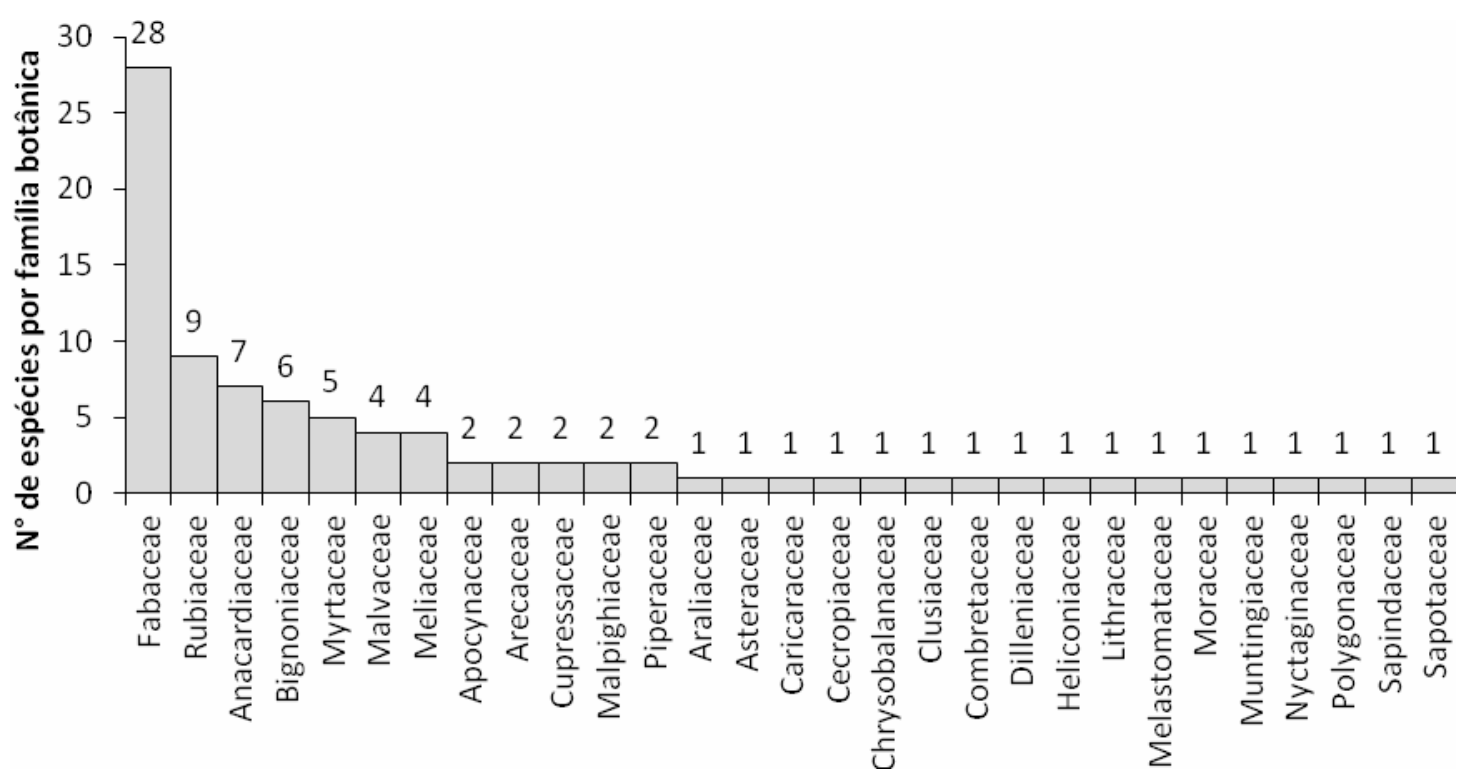

FIGURA 2. Número de espécies por família botânica encontradas no Parque Flamboyant, Goiânia, Goiás.

A riqueza de espécies arbóreas e arbustivas encontradas no parque Flamboyant (92 espécies em 492 plantas) é superior a maioria dos parques urbanos estudados no Brasil, mesmo em parques com maior área de conservação conforme ressaltado na Tabela 2. Um trabalho realizado em um fragmento urbano por TROIAN et al. (2011), na cidade de Cachoeirinha no Rio Grande do Sul, registrou 90 espécies arbóreas e 15 arbustivas, apenas nove eram exóticas. Na amostragem quantitativa, foram contempladas 54 espécies no estrato arbóreo e 45 no arbustivo, apresentando assim, uma elevada diversidade e equabilidade de espécies arbóreas.

Já OLIVEIRA-JÚNIOR et al. (2014), em um fragmento urbano em Capão Bonito, SP, amostraram 68 espécies, 33 gêneros e 24 famílias, utilizando o método ponto-quadrante, com os indivíduos arbóreos apresentando DAP $\geq 2,23 \mathrm{~cm}$. Neste estudo, os autores ressaltam que devido a alta diversidade florística, algumas espécies merecem atenção para que possam ser usadas em programas de recuperação de áreas degradadas.

TABELA 2. Caracteristicas ecológicas de diferentes parques urbanos no Brasil.

\begin{tabular}{ccccc}
\hline Estudo & Riqueza & Abundância & Famílias & Cidade \\
\hline Atual (2015) & 92 & 492 & 29 & Goiânia-Go \\
TROIAN et. al. (2011) & 105 & 268 & 25 & Cachoeirinha-RS \\
$\begin{array}{c}\text { OLIVEIRA-JÚNIOR et. } \\
\text { al. (2014) }\end{array}$ & 68 & 318 & 24 & Capão Bonito - SP \\
$\begin{array}{c}\text { PRADO-JÚNIOR et. al. } \\
\text { (2012) }\end{array}$ & 153 & 798 & 29 & Monte Carmelo - MG \\
SILVA et. al. (2007) & 58 & 981 & 35 & Recife - Pe \\
SILVA et. al. (2007) & 18 & 122 & - & Recife - Pe \\
SOUZA et al. (2011) & 64 & 1290 & 20 & Aracaju - SE \\
\hline
\end{tabular}


Em Monte Carmelo - Minas Gerais, o remanescente urbano abrangeu quatro fisionomias vegetais, totalizando 153 espécies e 29 famílias. Observou-se nesse estudo, o predomínio de espécies zoocóricas nas fisionomias e uma alta porcentagem de espécies anemocóricas no cerrado sentido restrito e cerradão (PRADO-JÚNIOR et al., 2012). Na cidade de Curitiba- PR foram avaliados 30 parques e bosques, analisando 5525 indivíduos arbóreos, sendo identificados 95,9\% até o nível de espécie. Dentre os cinco parques urbanos analisados nesse trabalho, - Passeio Público foi o que apresentou maior riqueza de espécies e menor dominância e equidade de espécies (BIONDI \& BOBROWSK, 2014).

Segundo SILVA et al. (2007), foram reconhecidas 87 morfoespécies de árvores, arvoretas e palmeiras em sete parques urbanos de Recife, com observação de 2808 indivíduos. No mesmo trabalho, os autores destacam que uma das espécies mais abundantes é a manga (Mangifera indica), que foi muito frequente no parque Flamboyant e muito utilizada na arborização urbana em todo país.

\section{CONCLUSÃO}

O Parque Flamboyant apresenta riqueza floristica considerável alta, comparável com outros parques urbanos e até mesmo outras unidades de conservação do Brasil. Assim, a conservação e manutenção do Parque Flamboyant torna-se relevante para a conservação da riqueza florística do Cerrado.

\section{REFERENCIAS}

AMMA, 2008. Plano diretor da arborização de Goiânia, Prefeitura de Goiânia. Agência Municipal do Meio Ambiente (AMMA). 134 p., 2008.

AMMA. Agência Municipal de Meio Ambiente de Goiânia. 2012. Disponível em: <http://www.goiania.go.gov.br/shtml/amma/apresentacao.shtml> Acesso feito dia 14/07/2015.

BARROSO, G. M.; PEIXOTO, A. L.; COSTA, C. G. ICHASO, C. L. F.; GUIMARÃES, E. F. \& LIMA, H. C. Sistemática das angiospermas do Brasil. V.2. UFV, Viçosa. p. 15-100. 1991.

BIONDI, D.; BOBROWSK, R. Utilização de índices ecológicos para análise do tratamento paisagístico arbóreo dos parques urbanos de Curitiba-PR. Enciclopédia Biosfera, Centro Científico Conhecer - Goiânia, v.10, n.18; p. 3006- 3017. 2014.

BRUN, F. G. K.; MUNIZ, M. B. Doenças em árvores e plantas ornamentais urbanas. Santa Maria: RS. Julho, 2006.

CARDOSO, S. L. C.; SOBRINHO, M. V.; VASCONCELLOS, A. M. DE A. Gestão ambiental de parques urbanos: o caso do parque ecológico do município de Belém Gunnar Vingren. Urbe. Revista Brasileira de Gestão Urbana (Brazilian Journal of Urban Management, p. 74-90. 2015

CORNELISSEN, T. G.; FERNANDES, G. W. Defence, growth and nutrient allocation in the tropical shrub Bauhinia brevipes (Leguminosae). Austral Ecology 26, p. 246253. 2001. 
FERREIRA, A. D. Efeitos positivos gerados pelos parques urbanos: o caso do passeio público do Passeio Público na cidade do Rio de Janeiro. Niterói: [s. n.], 2005.

FILGUEIRAS, T. S.; BROCHADO, A. L.; NOGUEIRA, P.E.; GUALA II, G. F. Caminhamento - um método expedito para levantamentos florísticos qualitativos. Cadernos de Geociências, v.2, n.4, p.39-43, 1994

FONSECA, N. Paclobutrazol e estresse hídrico no florescimento e produção de mangueira (Mangifera indica L.) "Tommy Atkins". Lavras: UFLA, 2002.

GRANDOLFO, V.A.; R.C. BOZZA-JUNIOR; SILVA-NETO, C.M.; MESQUITA-NETO, J.N. \& GONÇALVES, B.B. Riqueza e Abundância de Abelhas Euglossini (Hymenoptera, Apidae) em Parques Urbanos de Goiânia, Goiás. EntomoBrasilis, v. 6, p. 126-131, 2013

KLINK, C.A.; MACHADO, R.B. A conservação do cerrado brasileiro. Megadiversidade, v. 1, n.1, p. 147-155, 2005.

LOBODA, C. R.; DE ANGELIS, B. L. D. Áreas verdes públicas urbanas: conceitos, usos e Funções. Ambiência - Revista do Centro de Ciências Agrárias e Ambientais, v. 1 n. 1, 2005.

LORENZI, H. Árvores brasileiras: manual de identificação e cultivo de plantas arbóreas do Brasil, vol. 1/ 5. Ed. Nova Odessa, SP: Instituto plantarum, 2008.

LORENZI, H.; MOREIRA, H. Plantas ornamentais do Brasil: arbustivas, herbáceas e trepadeiras. São Paulo: Plantarium, p. 489-490. 1995.

LORENZI, H; SOUZA, H.M; TORRES, M.A.V.; BACHER, L.B. Árvores exóticas no Brasil: madeireiras, ornamentais e aromáticas. São Paulo: Nova Odessa. 2003.

LUND, J. B.; ANDREASSEN, A.; OTTOSEN, C. O.; AASLYNG, J. M. Effect of a dynamic climate on energy consumption and production of Hibiscus rosa-sinensis L. in greenhouses. Hortscience, p. 384-388, 2006.

MITTERMEIER, R.A., ROBLES, P., HOFFMANN, M., PILGRIM, J., BROOKS, T., MITTERMEIER, C.G., LAMOREUX, J. \& FONSECA, G.B. Hotspots Revisited: earth's biologically richest and most endangered ecoregions. Conservation International, Mexico City. 2005.

MATSUMOTO, M. L.; PEREIRA, Z. V.; GONÇALVES, J. P.; SANGALLI, A.; FERNANDES, S. S. L. Avaliação ambiental do parque urbano Arnulplho Fioravante para adoção de estratégias de restauração. Boletim Paranaense de Geociências, v. 67, p. 51-60, 2012. 
NEWSTROM, L.E.; FRANKIE, G.W.; BAKER, H.G. A new classification for plant phenology based on flowering patterns in Lowland Tropical Rain Forest Trees at La Selva, Costa Rica. Biotropica, St. Louis. v.26, n.2, p.141-159. 1994.

OLIVEIRA, M. A. DE. Parque Flamboyant: transformação da paisagem urbana em Goiânia/Goiás. 2011. 96 f. Dissertação (Mestrado em Ecologia e produção sustentável)- Pontifícia Universidade Católica de Goiás. Goiânia , 2011.

OLIVEIRA-JÚNIOR, S. B. DE; CERQUEIRA, R. M.; GIL, A. S. B.; VILHENA, N. Q. Composição florística e estrutural de uma mata ciliar em um fragmento urbano no município de Capão Bonito-SP. Enciclopédia Biosfera, Centro Científico Conhecer - Goiânia, v.10, n.19; p. 2059-2077. 2014.

PRADO-JÚNIOR, J. A. DO; LOPES, S. DE F.; VALE, V. S. DO; NETO, O. C. D.; SCHIAVINI, I.Comparação florística, estrutural e ecológica da vegetação arbórea das fitofisionomias de um remanescente urbano de cerrado. Bioscience Journal.Uberlândia, v. 28, n. 3, p. 456-471, Maio/Junho. 2012.

PEREIRA, B. A. DA S.; VENTUROLI, F.; CARVALHO, F. A. Florestas estacionais no cerrado: uma visão geral. Pesquisa Agropecuária Tropical. Goiânia, v. 41, n. 3, p. 446-455, jul./set. 2011.

PRADO, D. A. R. Parque municipal Flamboyant: Apropriação e usos para o lazer. 2012. 72 f. Dissertação (Mestrado em Geografia).Instituto de estudos socioambientais, Universidade Federal de Goiás. Goiânia, 2012.

RAMBALDI, D. M.; OLIVEIRA, D. A. S. Fragmentação de Ecossistemas: Causas, efeitos sobre a biodiversidade e recomendações de políticas públicas. Brasília: MMA/SBF, 2003. 510 p.

REZENDE, P. S.; SOUZA, J. DOS R. DE.; SILVA, G. O.; RAMOS, R. R.; SANTOS, D. G. DOS. Qualidade ambiental em parques urbanos: levantamento e análises de aspectos positivos e negativos do Parque Municipal Victório Siquierolli - Uberlândia MG. Revista Eletrônica de Geografia, v.4, n.10, p. 53-73, ago/ 2012.

SANTELLI, P. Fisiologia pós colheita de frutos das palmeiras Syagrus oleraceae (Mart.) Becc. e Mauritia vinifera Mart. 2005. 72 f. Dissertação (Mestrado em Botânica)- Instituto de Ciências biológicas, Universidade de Brasília. Brasília, 2005.

SILVA, D; FIGUEIREDO, P. N. Quantificação de visitantes florais de diferentes colorações. REB. Volume 3 (3): 75-92, 2010. Disponível em: < http://revistas.pucsp.br/index.php/reb/article/viewFile/30/3840> Acesso dia 22/06/2015.

SILVA, L. R. DA; MEUNIER, I. M. J.; FREITAS, A. M. DE M. Riqueza e densidade de árvores, arvoretas e palmeiras em parques urbanos de Recife, Pernambuco, Brasil. Revista da Sociedade Brasileira de Arborização e Urbanismo, Piracicaba, v.2, n.4, p. 34-49, dez/2007. 
SILVA, M. G. C. Florescimento e frutificaçõ da mangueira (Mangifera indica L.) Cv rosa promovidos por diferentes doses de paclobutrazol. UESB: 2006. 66p . il. Disponível em: <http://www.uesb.br/mestradoagronomia/banco-dedissertacoes/2006/maria-gerolina-conceicao-silva.pdf> Acesso feito dia 22/06/2015.

SILVA-NETO , C. M.; CARNEIRO, V. A.; PEREIRA, L. S.; GONÇALVES, BB . Floração de comunidade pirofítica no entorno do Parque Nacional da Chapada dos Veadeiros - Estado de Goiás, Brasil. Geoambiente On-line, v. 23, p. 33-45, 2014.

SILVEIRA, F. A. O.; SANTOS, J. C.; FRANCESCHINELLI, E. V.; FERNANDES, G.W. Vegetative and reproductive phenology of Bauhinia brevipes Vog.(Fabaceae). Biotropica (Submitted). 2007. In: SANTOS, J. C. Ecologia evolutiva da preferência e performance de insetos galhadores (Diptera: Cecidomyiidae) em Bauhinia brevipes Vog.(Fabaceae). Belo horizonte: MG, 2006.

SOUZA, A. L. de et al. Diagnóstico quantitativo e qualitativo da arborização das praças de Aracaju, SE. Revista Árvore, v. 35, n.6 , p. 1253-1263. 2011.

TROIAN, L. C.; KÄFFER, M. I.; MÜLLER, S. C.;TROIAN, V. R.; GUERRA, J.; RODRIGUES, G. G.; \& FORNECK, E. D. Florística e padrões estruturais de um fragmento florestal urbano, região metropolitana de Porto Alegre, RS, Brasil. Iheringia, Série Botanica, Porto Alegre, v. 66, n. 1, p. 5-16, julho 2011. 